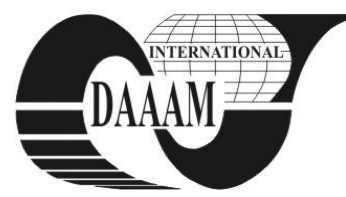

Annals of DAAAM for 2011 \& Proceedings of the 22nd International DAAAM Symposium, Volume 22, No. 1, ISSN 1726-9679 ISBN 978-3-901509-83-4, Editor B. Katalinic, Published by DAAAM International, Vienna, Austria, EU, 2011 Make Harmony between Technology and Nature, and Your Mind will Fly Free as a Bird Annals \& Proceedings of DAAAM International 2011

\title{
FLATTENING OF SILICON WAFERS
}

\section{DOBRESCU, T[iberiu] G[abriel]; NICOLESCU, A[drian] F[lorin]; PASCU, N[icoleta] \& DOBRE, D[aniel]}

\begin{abstract}
Most of today's IC (integrated circuit) chips are made from $200 \mathrm{~mm}$ or $150 \mathrm{~mm}$ silicon wafers. It is estimated that the transition from $200 \mathrm{~mm}$ to $300 \mathrm{~mm}$ wafers will bring a die cost saving of $30-40 \%$. A series of processes are required to manufacture high quality silicon wafers. As one of processes to flatten silicon wafers simultaneous double side grinding (SDGS) has a great potential to meet the demands for high quality wafers at low cost. This paper reviews manufacturing process flow for silicon wafers using SDGS and lapping. The interaction effects of three process parameters (wheel rotation speed, chuck rotational speed and federate) with surface roughness and grinding marks are presented
\end{abstract}

Key words: silicon wafers, lapping, grinding, polishing, flattening

\section{INTRODUCTION}

Manufacturing of silicon wafers starts with growth of silicon ingots. A sequence of processes is needed to turn an ingot into wafers (Dobrescu \& Dorin, 2008). This typically consists of following processes:

- Slicing, silicon ingot into wafers of this disk shape;

- Edge profiling (chamfering), to chamfer the peripheral edge portion of the wafer;

- Flattening (lapping or grinding), to achieve a high degree of parallelism and flatness of the wafer;

- Etching, to chemically remove the damage induced by slicing and flattering without introducing further mechanical damage;

- Rough polishing, to obtain a mirror surface on the wafer;

- Fine polishing, to obtain final mirror surface.

Two processes can be used to flatten the sliced wafers: lapping and simultaneous double side grinding (SDSG).

The lapping operation is shown in figure 1 .

The loaded wafers are then lapped by the abrasive slurry (typically a mixture of alumina and glycerin) injected between two lapping plates rotating in opposite directions.

The lapping operation would generate sub surface damages in silicon wafers, which need to be removed by its sub sequent processes. Simultaneous double side grinding is illustrated in figure 2. A pair of diamond cup wheels is located on the opposite side of a rotating silicon wafer. Both side of the rotating silicon wafer are ground simultaneously by the two wheels, which are synchronously fed towards the wafer.

Table 1 compares lapping and SDSD in five aspects. It can be seen that SDSG is better in almost every aspect.

\begin{tabular}{|l|l|l|}
\hline \multicolumn{1}{|c|}{ Characteristics } & \multicolumn{1}{c|}{ Lapping } & \multicolumn{1}{c|}{ SDSG } \\
\hline Waviness removal & Very good & Good \\
\hline Throughput & Low & High \\
\hline Consumable cost per wafer & High & Low \\
\hline Automation level & Low & High \\
\hline Environmental benignity & Poor & Good \\
\hline
\end{tabular}

Tab. 1. Comparison of different approaches for flattening silicon wafers

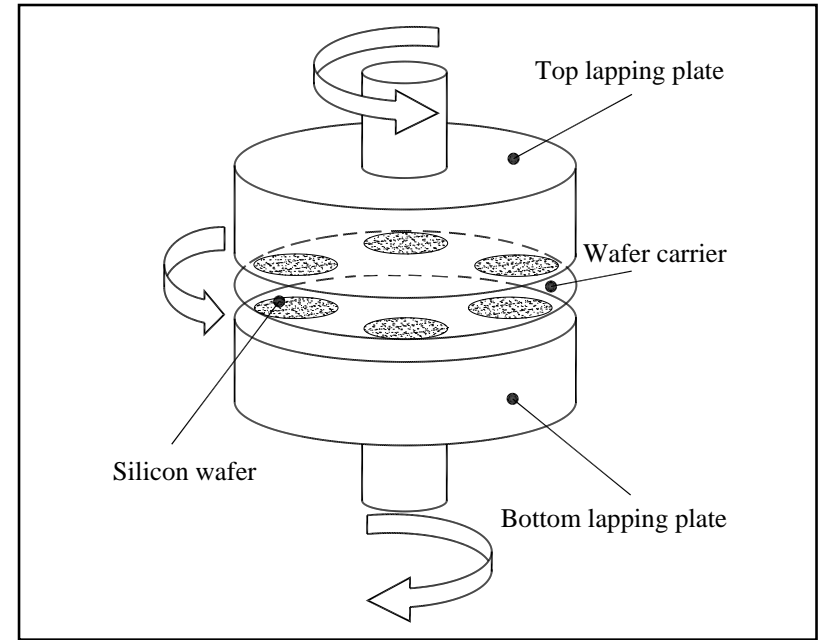

Fig. 1. Illustration of lapping process

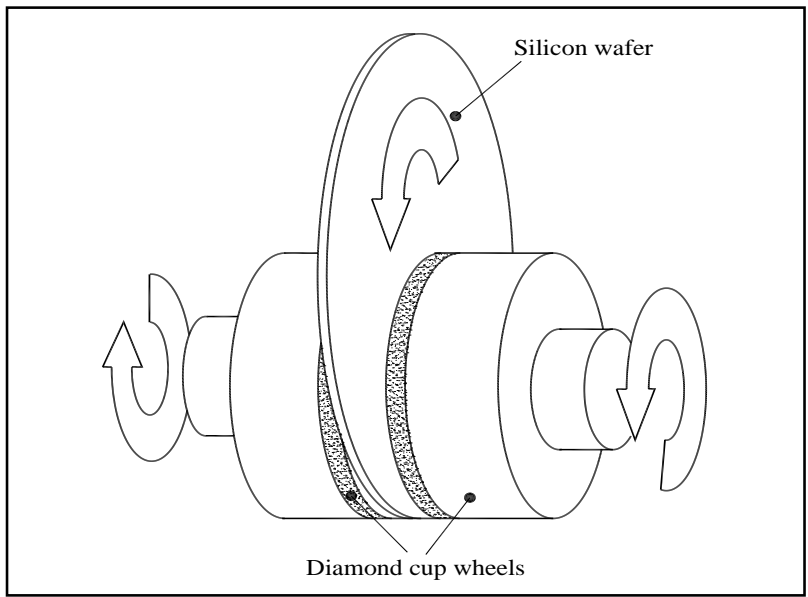

Fig. 2. Illustration of SDSG process

\section{PROCESS FLOWS USING SDGS}

SDSG was introduced into semiconductor industry in 1990s (Li et al., 2006). The diamond grinding wheels with different mesh size were used for different process flows:

- Slicing - SDSG - Lapping - Chamfering - Polishing;

- $\quad$ Slicing - SDSG - Lapping - Etching - Polishing;

- Slicing - SDSG - Chamfering - Etching - Polishing;

- Slicing - SDSG (fine) - Chamfering - SDSG (second) Etching - Polishing;

Since the main purpose of the coarse SDSG is stock removal, the diamond grits in the course wheels have large size (mesh \# $300-2000$ ). The mesh size of the wheels used in the fine SDSG process is in the range of \# $2000-10000$.

The bond materials for the SDSG wheels could be resin, metal or vitrified ceramic (Chidambaram et al., 2003). 


\section{THE EFFECTS OF PROCESS PARAMETERS ON GRINDING}

Grinding marks (figure 3), or grinding linear are the traces left by the grinding wheel on the wafer surface A (figure 3) and the "cress-cross" on the wafer surface B (Sun et al., 2004). In this paper only the distance between the adiacent lines of wafer surface A will be presented. Development of the model in this paper is based on the assumption that the grinding wheel behaves like a single-point tool. Two output variables are registered: grinding marks and surface roughness.

The major requirement for fine grinding of silicon wafers include: the grinding force should be low and constant; the grinding wheel should have a reasonable life; the ground wafers should have very good flatness; this usually means sub micron total thickness variation; surface and subsurface damage should be minimized (Dobrescu et al. 2009). The results on grinding marks are including in Table 2. We obtain the mathematical model for dependence. Actual grinding mark distance (GND) of wheel speed and respectively of wafer speed.

$$
\begin{gathered}
G M D=-0.01 n_{W}+51.685 \\
G M D=0.45 n_{W F}-11.5
\end{gathered}
$$

The distance between the grinding marks (GMD) decreases as the wheel speed $n_{W}$ increases. The effect of wheel speed is stranger at the high level of wafer speed for each output variable.

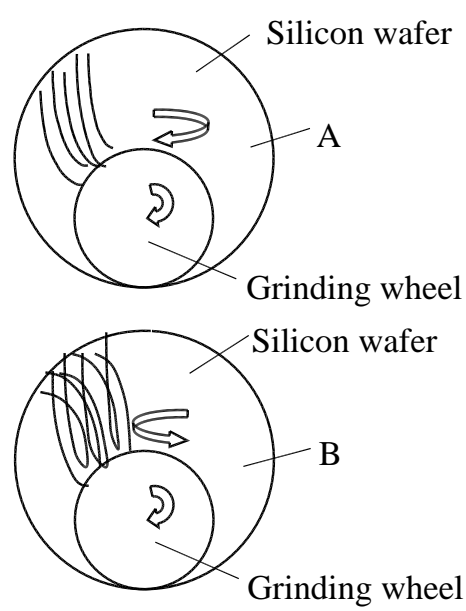

Fig. 3. Grinding marks

\begin{tabular}{|c|c|c|c|}
\hline Wheel speed & Wafer speed & Feed rate & $\begin{array}{c}\text { Grinding mark } \\
\text { distance }\end{array}$ \\
\hline+ & + & + & 22.39 \\
\hline+ & + & - & 22.28 \\
\hline+ & - & - & 5.53 \\
\hline- & - & + & 12.98 \\
\hline- & + & + & 51.08 \\
\hline- & + & - & 52.18 \\
\hline
\end{tabular}

Tab. 2. Grinding mark distance data

\begin{tabular}{|c|c|c|ccc|}
\hline $\begin{array}{c}\text { Wheel } \\
\text { speed }\end{array}$ & \multirow{2}{*}{$\begin{array}{c}\text { Wafer } \\
\text { speed }\end{array}$} & Feed rate & \multicolumn{2}{|c|}{ Surface roughness $\mathrm{R}_{\mathrm{a}}[\mathrm{nm}]$} \\
\cline { 4 - 6 } & & \multicolumn{2}{|c|}{ Wafer 1 } & Wafer 2 & Wafer 3 \\
\hline+ & + & + & 99 & 98 & 93 \\
\hline+ & + & - & 105 & 96 & 90 \\
\hline+ & - & - & 82 & 86 & 79 \\
\hline- & - & + & 170 & 160 & 182 \\
\hline- & + & + & 127 & 131 & 129 \\
\hline- & + & - & 92 & 96 & 88 \\
\hline
\end{tabular}

Tab. 3. Surface roughness data
Three process parameters are chosen to study their effects and interactions: the rotational speed of the grinding wheel, the rotational speed of the wafer and the federate of grinding wheel towards the wafer.

The results on surface roughness are included in Table 3. Surface roughness of the ground surface is measured along a direction approximately perpendicular to the grinding lines. The experiments are conducted on a Nanogrinder, Grinding Machines Nuremberg. The grinding wheel used is a diamond cap wheel. The grit size is mesh \# 1200 and the diameter of the wheel is $300 \mathrm{~mm}$. The instrument used is a Surf analyzer 5000 . The measurement is done at approximately the same location for each wafer. The main effects of wheel speed $n_{W}$ and feed rate $S$ are significant. Lower wheel speed and higher feed rate produce rougher surface as indicated the mathematical models:

$$
\begin{gathered}
R_{a}=-0.014 n_{W}+143 \\
R_{a}=100 S-25
\end{gathered}
$$

\section{CONCLUSION}

The following conclusions can be drowning:

- When the two grinding wheels rotated in different directions the surface on one side of the wafer was different from the other side. This was a limitation for SDSG if the identical wafer surface on both sides were required. But, the limitation could be reduced when the wheels rotated at a high speed report $\mathrm{n}_{\mathrm{W}} / \mathrm{n}_{\mathrm{WF}}>1$.

- Lower wheel speed and higher feed rate produce rougher surface.

- The distance between the grinding marks GMD is determined by wheel speed and wafer speed through the equation (1) respectively (2).

- In silicon wafer manufacturing, the removal amount of the subsequent polishing process to be large enough to eliminate all grinding marks generated in the SDSG operation.

Further reduction of polishing amount necessitates optimization of the grinding process so that the grinding marks can be eliminated with minimum amount of polishing

\section{REFERENCES}

Chidambaram, S.; Pei, Z. \& Kassir, S. (2003). Fine grinding of silicon wafers: a mathematical model for grinding marks, In: International Journal of Machine Tools \& Manufacture, No. 43, pag. 1595 - 1602

Dobrescu, T. \& Dorin, A. (2008). Flattening Process of Silicon Wafers, Annals of DAAAM for 2008 \& Proceedings of the 19th International DAAAM Symposium, 22-25th October 2008, Trnava, Slovakia, ISSN 1726-9679, ISBN 978-3901509-68-1, Katalinic, B. (Ed.), pp. 0375-0376, Published by DAAAM International Vienna, Vienna

Dobrescu, T.; Enciu, G. \& Nicolescu, A. (2009). Selection of Process Parameters in Grinding Ceramics, Annals of DAAAM for 2009 \& Proceedings of the 20th International DAAAM Symposium, 25-28th November 2009, Vienna, Austria, ISSN 1726-9679, ISBN 978-3-901509-70-4, Katalinic, B. (Ed.), pp. 0361-0362, Published by DAAAM International Vienna, Vienna

Li, Z.; Pei, Z. \& Fisher, G. (2006). Simultaneous double side grinding of silicon wafers: a literature review, In: International Journal of Machine Tools \& Manufacture, No. 46, pag. $1449-1458$

Sun, W.; Pei, Z. \& Fisher, G. (2004). Fine grinding of silicon wafers: a mathematical model for the wafer shape, In: International Journal of Machine Tools \& Manufacture, No. 44 , pag. $707-716$ 